Abstract-Little is known about the basic biology and ecology of most native lampreys, including the use of estuaries by anadromous lampreys. To address this deficiency, we provide the first analysis of anadromous western river (Lampetra ayresii) and Pacific (Entosphenus tridentatus) lampreys in the Columbia River estuary, using data from 2 fish assemblage studies that span 3 decades (1980-1981 and 2001-2012). Pacific lamprey juveniles and adults in the estuary clearly were separated by size, whereas western river lamprey formed one continuous size distribution. Pacific lamprey juveniles and adults were present in the estuary in winter and spring, and western river lamprey were present from spring through early fall. Depth in the water column also differed by lamprey species and age class. During 2008-2012, we documented wounds from lampreys on 8 fish species caught in the estuary. The most frequently wounded fishes were non-native American shad (Alosa sapidissima), subyearling Chinook salmon (Oncorhynchus tshawytscha), shiner perch (Cymatogaster aggregata), and Pacific herring (Clupea pallasii). This basic information on western river and Pacific lampreys in the Columbia River estuary adds to the growing body of regional research that should aid conservation efforts for these ancient species.

Manuscript submitted 9 January 2014. Manuscript accepted 27 February 2015. Fish. Bull. 113:213-226 (2015).

doi: 10.7755/FB.113.2.9

The views and opinions expressed or implied in this article are those of the author (or authors) and do not necessarily reflect the position of the National Marine Fisheries Service, NOAA.

\title{
Seasonal abundance, size, and host selection of western river (Lampetra ayresii) and Pacific (Entosphenus tridentatus) lampreys in the Columbia River estuary
}

\author{
Laurie A. Weitkamp (contact author) ${ }^{1}$ \\ Susan A. Hinton ${ }^{2}$ \\ Paul J. Bentley² \\ Email address for contact author: laurie.weitkamp@noaa.gov \\ 1 Conservation Biology Division \\ Northwest Fisheries Science Center \\ National Marine Fisheries Service, NOAA \\ 2032 Marine Science Drive \\ Newport, Oregon 97365 \\ 2 Fish Ecology Division \\ Northwest Fisheries Science Center \\ National Marine Fisheries Service, NOAA \\ 520 Heceta Place \\ Hammond, Oregon 97121
}

Two native lamprey species are widely distributed along the west coast of North America: western river lamprey (Lampetra ayresii; formerly river lamprey) and Pacific lamprey (Entosphenus tridentatus) (Wydowski and Whitney, 2003). Like most lampreys (family Petromyzontidae), both of these species have complex life cycles that include an extended larval stage (the ammocoete stage) and a relatively brief adult stage (Hardisty, 2006). Both western river and Pacific lampreys are anadromous and parasitic as adults (Beamish, 1980; Wydowski and Whitney, 2003); however, many details concerning their life cycle and ecology are poorly understood, and most available information comes from a few geographic areas (Beamish, 1980; Hayes et al., 2013).

Pacific lamprey ammocoetes spend 3-7 years in riverine sediments before metamorphizing into juveniles, migrate downstream to spend 3-4 years in marine waters, and spawn 1 year after re-entering freshwater (Beamish, 1980; Beamish and Levings, 1991). Compared with Pacific lamprey, western river lamprey have a much shorter ocean residence (3-4 months), adults are much smaller, and timing of transitions between life stages differs (Beamish, 1980; Hayes et al., 2013). During the parasitic phase, the mode of feeding also differs between the 2 species: $\mathrm{Pa}$ cific lamprey consume their host's blood, but western river lamprey bite off pieces of flesh (Cochran, 1986; Beamish and Neville, 1995).

Concerns about declining native lamprey populations across North America in general (Renaud, 1997), and in the Columbia River in particular (Close et al., 2002; Moser and Close, 2003), have led to recent efforts to restore and conserve native lamprey populations and identify specific information needed to ensure their continued existence (Close et 
al., 2002; Kostow ${ }^{1}$; Mesa and Copeland, 2009). Pacific lamprey in the Columbia River have been the focus of much of this work because of the cultural importance of this species for Native American tribes in the basin and the documented decline in adults counted crossing Columbia River dams (Close et al., 2002; Moser and Close, 2003). In contrast, very little is known about the biology or status of the western river lamprey, to the extent that its continued existence in Oregon has been questioned (Kostow ${ }^{1}$ ).

Although there is considerable effort underway to understand the habitat requirements of lampreys in freshwater (e.g., Streif, 2009; Jackson and Moser, 2012), very little is known about estuarine and marine ecology for most lamprey populations (Mesa and Copeland, 2009; Murauskas et al., 2013; Siwicke, 2014), including those in the Columbia River. Information on estuarine ecology is necessary to understand this fundamental stage of the life cycle and is essential to document the timing of transitions between freshwater and marine habitats. Lampreys can also be parasitic in estuaries, yet very little is known about these parasite-host relationships outside of the Fraser River (Beamish, 1980; Beamish and Neville, 1995).

To address the paucity of basic information on lampreys in the Columbia River estuary, we used 2 data sets from the systematic sampling of the estuarine fish assemblage to document use of the estuary by western river and Pacific lampreys. We also describe fishes with lamprey wounds observed over a 5-year period. Although far from comprehensive, this work begins to fill a critical information gap about lampreys in the Columbia River estuary and provides an important contribution to knowledge of the life history of these ancient-and culturally and ecologically important-species.

\section{Materials and methods}

\section{Fish collections}

Juvenile and adult lamprey data used in our analysis came from 2 studies: the Columbia River Estuary Data Development Program (CREDDP) in 1980-1981 and the Estuary Purse Seine (EPS) study during 20012012. The CREDDP was a large, multifaceted research effort designed to increase understanding of the ecology of the Columbia River estuary. It consisted of 13 integrated projects, ranging from quantifying benthic primary production to modeling circulation (Bottom et al. ${ }^{2}$ ). We were able to access archived raw biological

\footnotetext{
${ }^{1}$ Kostow, K. 2002. Oregon lampreys: natural history, status, and analysis of management issues, 80 p. Oregon Dep. Fish Wildl. Inf. Rep. 2002-01. [Available from http://www. dfw.state.or.us/fish/species/docs/lampreys2.pdf.]

2 Bottom, D. L., K. K. Jones, and M. J. Herring. 1984. Fishes of the Columbia River estuary: final report on the Fish Work Unit of the Columbia River Estuary Data Development Program, 113 p. Columbia River Estuary Data Development
}

data collected by the NOAA Fisheries Northwest Fisheries Science Center during this study.

The primary fish project of CREDDP was an 18-month-long effort devoted to better defining pelagic and demersal components of the estuarine assemblage (Bottom et al. ${ }^{2}$ ). Fishes were collected monthly from February 1980 through July 1981 at 22 bottom trawl and 16 purse seine sites. One haul or set was conducted at each site each month; therefore, the months of February-July were each sampled twice (once in 1980, once in 1981) and the months of August-January were sampled only once. The CREDDP included beach seine and fyke net sampling, but catches of lampreys in both gears were low $(n=4)$ and were not included in our analysis. Sampling sites in the Columbia River were located from river $\mathrm{km}(\mathrm{rkm}) 3.8$ through $\mathrm{rkm} 58.2$ ( $\mathrm{rkm} 0$ is the west end of the jetties) (Fig. 1) and were chosen to represent a diversity of habitats within the estuary.

A semiballoon shrimp trawl (38.1-mm stretched mesh, knotless 12.7-mm liner) with an 8-m head rope was towed upstream during flood tide for $5 \mathrm{~min}$ during CREDDP sampling. A purse seine $(200 \times 9.8 \mathrm{~m})$ with variable knotless mesh (19.0 and $12.7 \mathrm{~mm}$ ) was towed upstream for $5 \mathrm{~min}$ before the net was pursed (Bottom et al. ${ }^{2}$ ). All collected fish were identified to species according to standard fish identification references (e.g., Hart, 1973; Scott and Crossman, 1973), enumerated, and released. Up to 50 individuals of each species were restrained or anaesthetized (juvenile salmon only), measured, (fork length [FL] or total length [TL] in millimeters, weighed (weight in grams), and released. Eyed lampreys were identified to species by dentition; ammocoetes, in which developing eyes are covered with skin, were grouped into a single category.

The EPS study in the lower Columbia River estuary was conducted during 2001-2012, although no sampling occurred in 2004 and 2005. The study objectives during 2001-2003 were to document presence and abundance of forage fishes in the lower estuary (S. Hinton, unpubl. data), but objectives changed in 2007 to assess presence and abundance of juvenile salmon, with particular emphasis on the spring outmigration (Weitkamp et al., 2012). Accordingly, sampling during 2001-2003 occurred twice monthly from midApril through September. The sampling interval during 2007-2012 was highest during the spring (every 2 weeks from mid-April through late June), with an additional sampling cruise in September during 20072008 and approximately monthly sampling from July through October during 2009-2012. The sampling during 2001-2003 was conducted at 4 sampling stations in the lower estuary (Sand Island [rkm 7], Desdemona Sands [rkm 16], North Channel [rkm 17], and Trestle Bay [rkm 13]), and the sampling during 2007-2012 was conducted at only 2 sampling stations (Trestle Bay and North Channel) (Fig. 1). Sampling depths also changed over the course of this study, with fish sampled in

Program. [Available from Columbia River Estuary Study Taskforce, P.O. Box 175, Astoria, OR 97103.] 


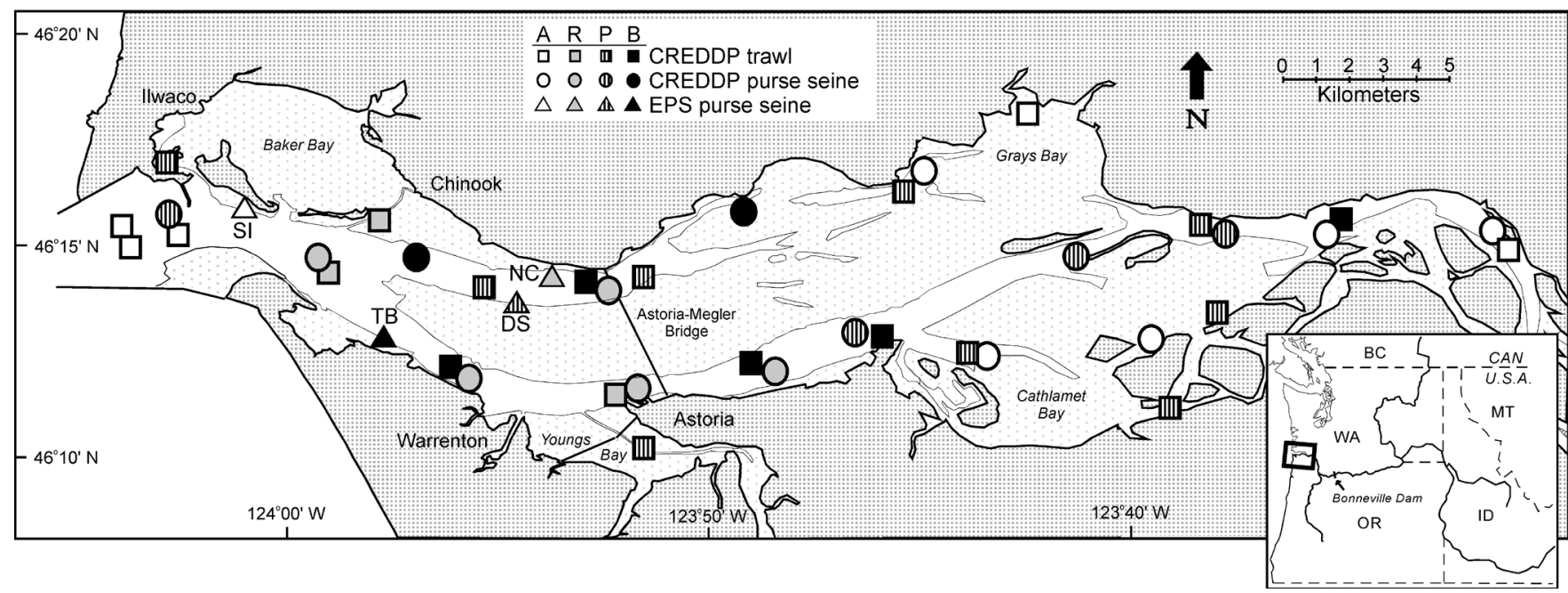

Figure 1

Map of the study area in the lower Columbia River estuary, showing the location of the Columbia River Estuary Data Development Program (CREDDP) trawl and purse seine sites sampled during 1980-1981 and the 4 Estuary Purse Seine (EPS) study sites sampled during 2001-2012. Presence of western river (Lampetra ayresii) and Pacific (Entosphenus tridentatus) lampreys at each station is indicated by shading; $A=$ both species absent; $\mathrm{R}=$ western river lamprey only present; $\mathrm{P}=\mathrm{Pacific}$ lamprey only present; B=both species present. The EPS sites were located at Sand Island (SI), Trestle Bay (TB); North Channel (NC); and Desdemona Sands (DS). The inset map shows the locations of the Columbia River basin and estuary and Bonneville Dam. State and province abbreviations: WA=Washington; OR=Oregon; ID=Idaho; MT=Montana; and BC=British Columbia.

depths that were shallower during 2001-2002 (mean: $5.1 \mathrm{~m}$ ) than during 2003-2012 (mean: $8.9 \mathrm{~m}$ ) (Table 1). Sampling in 2006 was limited to sampling trips in July and August at a single station (Trestle Bay).

During the EPS study, each sampling trip (or cruise) consisted of a series of hauls (individual sampling events) conducted over 1-4 days. During 2001-2003, each station was sampled at least twice during each cruise, and, during 2007-2012, 5-9 hauls were made at each of the 2 stations during each cruise. Sampling gear in the EPS study was restricted to fine-mesh purse seines. The purse seine used during 2001-2002 was shorter and shallower $\left(100 \mathrm{~m} \times 4.6 \mathrm{~m}\right.$; area: $\left.796 \mathrm{~m}^{2}\right)$ than the seine used during 2003 and 2006-2012 (155 $\mathrm{m} \times 10.6 \mathrm{~m}$; area: $1912 \mathrm{~m}^{2}$ ); but the mesh size of both nets was identical throughout (stretched mesh opening: $17 \mathrm{~mm}$; knotless bunt mesh: $15 \mathrm{~mm}$ ). Two methods were used to set the net: 1) during quantitative round hauls, it was set in a circle, and 2) in nonquantitative hauls, it was towed upstream for $10 \mathrm{~min}$ before it was pursed to increase the catch. Both methods were used during a cruise, and a minimum of 6 quantitative round hauls were made per cruise.

Fish processing in the EPS study was similar to that in the CREDDP: all fish were identified to species and enumerated, a subsample was measured, and the remainder were released; eyed lampreys were identified by dentition (Hart, 1973). Juvenile Chinook salmon (Oncorhynchus tshawytscha) were segregated into 2 age categories (subyearling [age 0] and yearling [age 1]) on the basis of seasonally adjusted fish length cutoffs (Weitkamp et al., 2012) because subyearling and yearling Chinook salmon differ in many life history traits, including degree of estuarine residency (Quinn, 2005).

Although the catch of lampreys was recorded in all years, recognizing and recording lamprey wounds on fishes did not begin until 2008 for all fishes or 2006 for juvenile salmon. We tallied only the fresh wounds that we were confident were due to lamprey predation because of their shape (circular or oval) and location on the body (back or sides) (Cochran, 1986; Beamish and Neville, 1995; Siwicke, 2014); scars (wounds with healed skin) were excluded. All the lamprey wounds that we identified were classified as type A, stage I or II (King, 1980): wounds with broken skin that exposed the underlying musculature and occasionally wounds with active bleeding. Verification that observed wounds were likely due to lamprey predation was confirmed from photographs by Moser ${ }^{3}$. Because of time constraints, the presence of lamprey wounds on a fish was recorded but details about wound location or depth were not collected (e.g., Orlov et al., 2009; Siwicke, 2014). Other common wounds observed on fishes included those due to marine mammals, avian predators, or unknown sources.

\section{Data analysis}

Our analysis was twofold: 1) we evaluated annual occurrence, seasonal abundance, and size (using CREDDP and EPS data) and the distribution (using CRED-

\footnotetext{
${ }^{3}$ Moser, M. 2012. Personal commun. Northwest Fish. Sci. Cent., Natl. Mar. Fish. Serv., 2725 Montlake Blvd. E., Seattle, WA 98112-2097.
} 


\section{Table 1}

Sampling effort, mean depths of sampling, and percent frequency of occurrence (\%) and total numbers $(n)$ of Pacific lamprey (Entosphenus tridentatus) adults and juveniles and western river lamprey (Lampetra ayresii) caught in the lower Columbia River estuary by year and gear type. Sampling occurred during 1980-1981 as part of the Columbia River Estuary Data Development Program (CREDDP) and in 2001-2012 during the Estuary Purse Seine (EPS) study. The 2 gear types used were purse seine (P) and trawl (T).

\begin{tabular}{|c|c|c|c|c|c|}
\hline \multirow{3}{*}{$\begin{array}{l}\text { Year and } \\
\text { net type }\end{array}$} & \multirow{3}{*}{$\begin{array}{l}\text { Number } \\
\text { of hauls }\end{array}$} & \multirow[b]{3}{*}{ Depth $(\mathrm{m})$} & \multicolumn{3}{|c|}{ Frequency of occurrence $(\%)$} \\
\hline & & & \multicolumn{2}{|c|}{ Pacific lamprey $(n)$} & \multirow{2}{*}{$\begin{array}{c}\text { Western river } \\
\text { lamprey }(n)\end{array}$} \\
\hline & & & Adults & Juveniles & \\
\hline \multicolumn{6}{|l|}{ CREDDP } \\
\hline 1980-T & 241 & 11.9 & $9.1(1)$ & $18.2(21)$ & $54.5(11)$ \\
\hline 1981-T & 153 & 12.2 & $0.0(0)$ & $66.7(12)$ & $66.7(7)$ \\
\hline 1980-P & 171 & 14.0 & $27.3(5)$ & $18.2(2)$ & $54.5(22)$ \\
\hline 1981-P & 109 & 14.0 & $16.7(1)$ & $0.0(0)$ & $16.7(2)$ \\
\hline \multicolumn{6}{|l|}{ EPS } \\
\hline 2001-P & 79 & 5.1 & $0.0(0)$ & $0.0(0)$ & $0.0(0)$ \\
\hline 2002-P & 78 & 5.1 & $0.0(0)$ & $10.0(1)$ & $0.0(0)$ \\
\hline 2003-P & 54 & 7.5 & $0.0(0)$ & $0.0(0)$ & $30.8(7)$ \\
\hline 2006-P & 13 & 7.5 & $0.0(0)$ & $0.0(0)$ & $33.3(5)$ \\
\hline 2007-P & 91 & 9.4 & $0.0(0)$ & $0.0(0)$ & $42.9(6)$ \\
\hline 2008-P & 95 & 8.7 & $0.0(0)$ & $0.0(0)$ & 62.5 \\
\hline 2009-P & 102 & 9.1 & $20.0(2)$ & $0.0(0)$ & $10.0(3)$ \\
\hline 2010-P & 98 & 8.9 & $0.0(0)$ & $11.1(1)$ & $22.2(6)$ \\
\hline 2011-P & 125 & 9.0 & $0.0(0)$ & $0.0(0)$ & $9.1(1)$ \\
\hline 2012-P & 85 & 9.0 & $0.0(0)$ & $0.0(0)$ & $33.3(5)$ \\
\hline
\end{tabular}

DP data only) of western river and Pacific lampreys caught in the Columbia River estuary, and 2) we documented the size and seasonal abundance of fishes with lamprey wounds and their co-occurrence with lampreys (EPS data only).

Lamprey abundance and size Investigation of the sizes of Pacific lamprey revealed 2 clearly separated groups, which we designated as juveniles $(<160 \mathrm{~mm} \mathrm{TL})$ and adults (>400 $\mathrm{mm}$ TL), according to reported sizes for each age class in the literature (Beamish, 1980; Farlinger and Beamish, 1984; Kostow ${ }^{1}$ ). Because the 2 groups of Pacific lamprey did not overlap in size and we expected their use of the estuary to differ, we analyzed smaller juveniles and larger adults separately as different age classes. In contrast, one continuous size distribution was observed for western river lamprey, which were treated as a single age class. This latter group likely included individuals that were moving downstream (juveniles) and upstream (adults), but there was no clear break in the size distribution to indicate where to differentiate between juveniles and adults.

To determine variation in the presence of western river lamprey and juvenile and adult Pacific lamprey in the estuary, we first estimated frequency of occurrence (FO) for each species and age class for each year as the total number of cruises in which at least one lamprey was caught, divided by the total number of cruises conducted each year with each gear type, expressed as a percentage. For CREDDP data, each month of sampling was treated as a cruise, and, for EPS data, as described previously, each sampling trip was considered a cruise.

To document seasonal abundance, we calculated mean monthly density (individuals/ $10,000 \mathrm{~m}^{2}$ ) as the number of lamprey of each species, and of age class for Pacific lamprey, caught each month by each study or gear type, divided by effort and averaged across all years. Effort was calculated as the number of sets conducted each month multiplied by the area swept during each set by gear type. Because we wanted to include lampreys caught during nonquantitative tows of the EPS study $(n=14)$ in our density estimates, we needed to estimate the area covered during tows. We did so by calculating the ratio of the number of all fish caught in tows to the number of all fish caught in quantitative round hauls made immediately before or after the tow. For tows in which at least one lamprey was caught, this ratio averaged 3.1; therefore, tows were estimated to encompass $5927 \mathrm{~m}^{2}\left(3.1 \times 1912 \mathrm{~m}^{2}\right)$, when using the longer EPS purse seine. Estimates of density should be interpreted with caution, however, because all density estimates were based on the assumption that lampreys of both species and age classes are equally vulnerable to all net types-an assumption that is unlikely to be 
true. Therefore, we viewed densities as indicators of relative abundance, rather than of absolute abundance and did not quantitatively compare densities between studies or gear types.

Because the CREDDP sampling sites were distributed throughout the estuary, we used station-specific catch data to calculate the mean location ( $\mathrm{rkm}$ ) for each species and age class of lamprey. Differences between groups were evaluated by using Kruskal-Wallis (KW) one-way analysis of variance (ANOVA) on ranks, followed by a Bonferroni multiple comparison test if significant differences were detected (Zar, 1984).

Finally, we wanted to determine whether the size of western river lamprey differed by study or gear type, in part because such variation in size may indicate differences in life history or gear selectivity. However, because the length of western river lamprey increased over the sampling season, we used analysis of covariance (ANCOVA) for these comparisons, with ordinal date as a covariate (Sokal and Rohlf, 1995). We tested whether the mean size and change in size over time (i.e., slope) of western river lamprey varied between the CREDDP and EPS studies and between gear types (purse seine versus trawl) for the CREDDP. This analysis produced adjusted means for each group (study or gear type), which were adjusted for the effect of the covariate (ordinal date) for that group by using linear regression procedures (Sokal and Rohlf, 1995).

Prey selectivity by lampreys Our analysis of fishes with lamprey wounds was designed to determine 1) the frequency of wounded fish of each species overall, 2) whether there was a seasonal pattern to the presence of wounded fishes, and 3) whether lampreys appeared to be selecting fishes of a particular size. We also examined the frequency with which lampreys were caught together with wounded prey as an additional measure of the seasonality of lamprey predation.

We examined the frequency of lamprey wounds by comparing the abundance of a particular fish species with and without wounds at annual and seasonal time scales. For annual estimates, we first determined the number of cruises in which fish with lamprey wounds were observed and divided that number by the number of cruises in which fish of that species were caught (with or without wounds) each year. We also calculated the percentage of fish with and without wounds caught during each cruise for each species and averaged the values over cruises in which at least one wounded fish was observed. This estimate was based on total catches of 21,484 surf smelt (Hypomesus pretiosus), 19,816 American shad (Alosa sapidissima), 7422 Pacific herring (Clupea pallasii), 4380 subyearling Chinook salmon, 2696 shiner perch (Cymatogaster aggregata), 1231 steelhead (O. mykiss), 681 longfin smelt (Spirinchus thaleichthys), and 106 sockeye salmon (O. nerka). To explore seasonality in lamprey wounds on the most frequently wounded species, we calculated the number of fish of a given species with wounds divided by the total number of fish of that species caught within each 2-week period of each year (1 April-15 October), and then we averaged the values across years.

To determine whether there was size selectivity in host choice by lampreys, we compared the size of fish (of a particular species) with lamprey wounds with the size of fish (of the same species) without wounds from the same cruise using a Mann-Whitney test of medians (MW; Zar, 1984). Low numbers of wounded fish of a particular species from a single cruise, however, resulted in low statistical power. Because the size of most fishes increased over the course of the summer, we also we used a nonparametric Friedman test (an ANOVA analog) to test for size differences between fish with and without wounds; cruise was treated as a block (So$\mathrm{kal}$ and Rohlf, 1995). We used probabilities of $\alpha<0.05$ as the significance level for both tests. We also examined the overlap between catches of lampreys and wounded fishes both by haul and by cruise.

\section{Results}

\section{Lampreys in the Columbia River estuary}

During the 18-month-long CREDDP, 42 western river lamprey and 42 Pacific lamprey (35 juveniles and 7 adults) were caught. During the EPS study, 44 western river lamprey and 4 Pacific lamprey (2 juveniles and 2 adults) were caught over 10 years (Table 1 ). One lamprey ammocoete (of an unidentified species) was caught during the CREDDP.

The frequency of occurrence (FO) of lampreys in the Columbia River estuary varied in both studies by species, age class, and year and in CREDDP, by gear type (Table 1). Within the EPS study, FO reflected the infrequent catch of Pacific lamprey (mean FO: 2.1\%) and the frequent and relatively consistent catch of western river lamprey (mean FO: 24.4\%). Although no western river lamprey were encountered during 2001 and 2002 , at least one western river lamprey was caught during nearly one-third of all cruises conducted during 2003-2012 (mean FO: 29.8\%). During the CREDDP, catch of the different species and age classes varied by gear type and to a lesser extent by year (Table 1). The FO for Pacific lamprey juveniles was much higher in trawls (mean FO: 42.4\%) than in purse seines (mean FO: 9.1\%), higher for Pacific lamprey adults in purse seines (mean FO: 22.0\%) than for adults in trawls (mean FO: $4.6 \%$ ), and relatively high for western river lamprey in both purse seines (mean FO: $35.6 \%$ ) and trawls (mean FO: 60.6\%) (Table 1).

The density of western river and Pacific lamprey juveniles and adults exhibited clear seasonal patterns that were consistent across 3 data sets: the data set from EPS (purse seine) study and 2 subsets of data from CREDDP (trawl and purse seine) study (Fig 2). Adult Pacific lamprey had the highest densities during January-March and lower densities during April-May, and no adults were caught during June-December. Ju- 


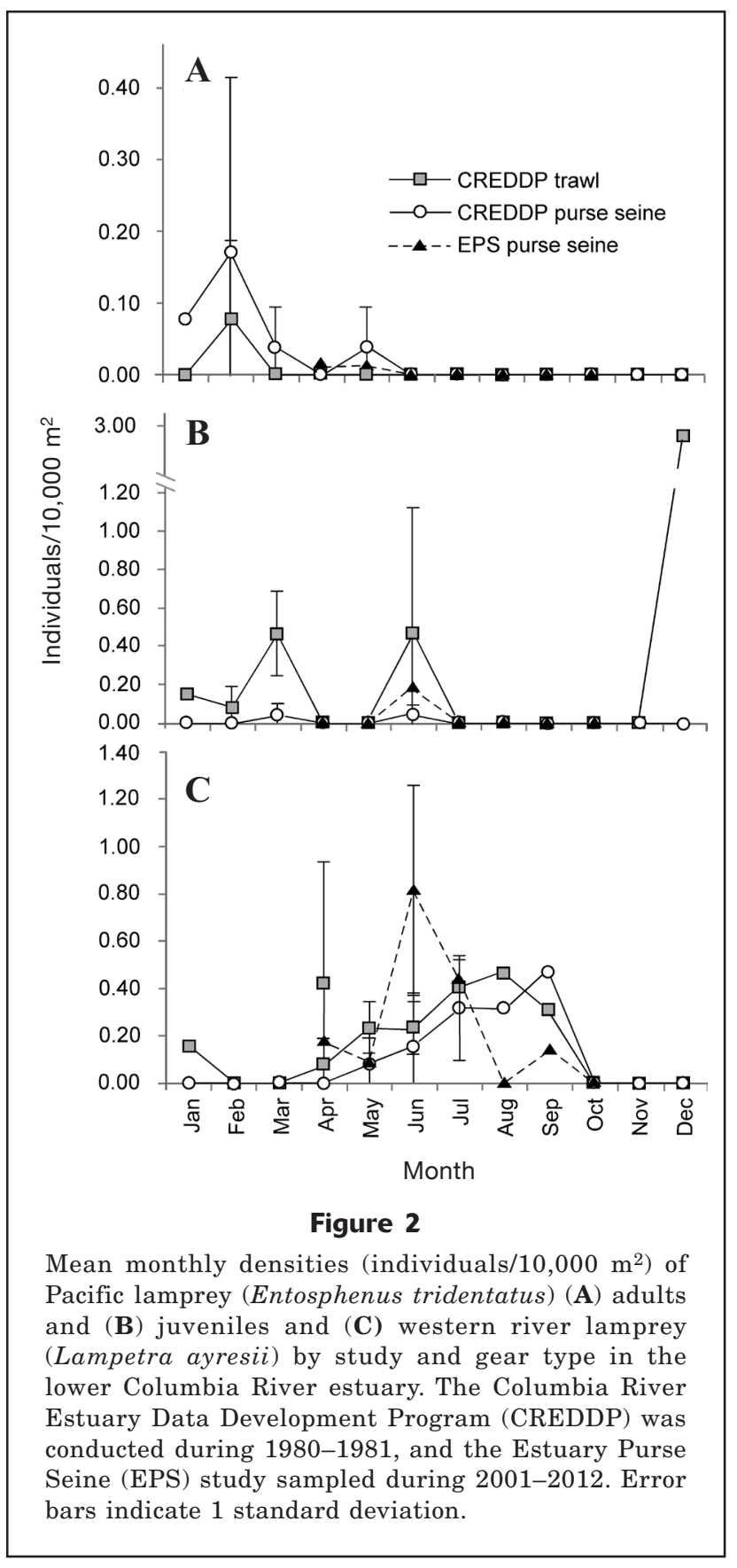

venile Pacific lamprey showed the highest densities in December and lower densities during January-March; a few individuals were captured in June. High densities of juveniles documented in December 1980 were spread across 8 stations sampled over 5 days, indicating a large continuous surge of juveniles in the estuary rather than a single, isolated concentration of individuals. Lastly, western river lamprey were present in the estuary over 6 months (April-September) in data sets from both studies, but there was a slightly earlier density peak in the EPS study (June) than in the CREDDP study (August or September; Fig. 2). A single western river lamprey was also caught by the CREDDP trawl in January, but no parallel catches were observed in the CREDDP purse seine.

The spatial distribution of both western river and Pacific lampreys within the Columbia River estuary was evaluated with data from the many CREDDP stations (Fig. 1). Abundances of Pacific lamprey juveniles and adults were centered at rkm 21.8 and 31.8 , respectively, and the average location for western river lamprey was rkm 20.0. The difference in mean location between western river and adult Pacific lampreys was statistically significant (MW: $H=7.9, P<0.05$ ), but the difference between Pacific lamprey juveniles and the other groups (Pacific lamprey adults and western river lamprey) was not (MW: $H \leq 1.1, P>0.1$ ). All 3 groups were widely distributed throughout the estuary, but neither species was recorded at the most downsteam (rkm 3.8) or upstream (rkm 58.2) trawl and purse seine sites (Fig. 1).

The mean lengths of lampreys caught in the Columbia River estuary across both studies were $132.8 \mathrm{~mm}$ TL (range: $102-157 \mathrm{~mm} \mathrm{TL}$ ) and $596.0 \mathrm{~mm}$ TL (range: 401-745 mm TL) for juvenile and adult Pacific lamprey, respectively, and $198.1 \mathrm{~mm}$ TL (range: 102-324 $\mathrm{mm} \mathrm{TL}$ ) for western river lamprey. Length and weight data from the CREDDP showed the same patterns: Pacific lamprey juveniles, on average, were $132.8 \mathrm{~mm}$ TL and weighed $3.6 \mathrm{~g}$; mean values for adults were 605.2 $\mathrm{mm}$ TL and $460.2 \mathrm{~g}$ and for western river lamprey were $211.7 \mathrm{~mm}$ TL and $19.2 \mathrm{~g}$.

The size of western river lamprey differed by study and gear type. Western river lamprey caught in the CREDDP (regardless of gear) were longer (adjusted mean: 206.3 $\mathrm{mm}$ TL; $n=41$ ) and increased over time at a steeper rate $(0.84 \mathrm{~mm} / \mathrm{d})$ than those caught during the EPS study (adjusted mean: $189.5 \mathrm{~mm}$ TL; slope $=0.27 \mathrm{~mm} / \mathrm{d} ; n=42$; ANCOVA: $F \geq 3.8, P<0.05)$. Within the CREDDP, western river lamprey caught with trawls (adjusted mean: $189.7 \mathrm{~mm}$ TL; $n=18$ ) were significantly smaller than were those caught with purse seines (adjusted. mean: 224.0; ANCOVA test of means: $F=6.4, P<0.05$ ). It is not clear whether these size differences between studies and gear types reflect differences in size selectivity of gears, size differences between individuals occupying different parts of the water column, or differences in the lamprey population over time.

\section{Fishes with lamprey wounds}

We observed lamprey wounds on 142 individual fishes representing 8 species (Table 2, Fig. 3). The highest absolute number of wounded fish by species occurred in non-native American shad (71 wounded fish), followed by subyearling Chinook salmon (33), shiner perch (25), and Pacific herring (8). Other species with wounds included juvenile steelhead (2), juvenile sockeye salmon (1), surf smelt (1), and longfin smelt (1) (Table 2). The frequency of lamprey wounds by cruise was highest for shiner perch; wounded individuals were observed in $41 \%$ of all cruises in which at least one shiner perch 


\begin{tabular}{|c|c|c|c|c|}
\hline \multicolumn{5}{|c|}{$\begin{array}{l}\text { Number of fishes observed with lamprey wounds, by species, in the lower Columbia River estuary } \\
\text { during the Estuary Purse Seine study during } 2008-2012 \text { or } 2006-2012 \text { (Chinook salmon only). Also } \\
\text { provided are the mean percentages of fish of each species with wounds and, for each species, the per- } \\
\text { centage of cruises in which at least one wounded fish was observed. }\end{array}$} \\
\hline Common name & Scientific name & $\begin{array}{l}\text { Number of } \\
\text { fish with } \\
\text { wounds }\end{array}$ & $\begin{array}{l}\text { Mean percentage } \\
\text { of fish with } \\
\text { wounds }\end{array}$ & $\begin{array}{l}\text { Percentage of } \\
\text { cruises with } \\
\text { wounded fish }\end{array}$ \\
\hline American shad & Alosa sapidissima & 71 & 0.27 & 40.0 \\
\hline Chinook salmon & Oncorhynchus tshawytscha & 33 & 0.84 & 37.3 \\
\hline Shiner perch & Cymatogaster aggregata & 25 & 5.05 & 40.7 \\
\hline Pacific herring & Clupea pallasii & 8 & 0.07 & 9.8 \\
\hline Steelhead & Oncorhynchus mykiss & 2 & 0.19 & 7.1 \\
\hline Longfin smelt & Spirinchus thaleichthys & 1 & 0.19 & 4.8 \\
\hline Sockeye salmon & Oncorhynchus nerka & 1 & 0.42 & 6.7 \\
\hline Surf smelt & Hypomesus pretiosus & 1 & 0.02 & 2.2 \\
\hline
\end{tabular}

was caught (11 of 27 cruises), followed by American shad (40\%; 16 of 40 cruises), subyearling Chinook salmon (37\%; 19 of 51 cruises), and Pacific herring (10\%, 4 of 41 cruises) (Table 2). When the number of fish of a particular species with lamprey wounds were compared with the total number of individuals of that species caught by cruise, the species with the highest average percentage of fish with lamprey wounds, by cruise, was shiner perch $(5.1 \%)$, followed by Chinook salmon $(0.8 \%)$, sockeye salmon $(0.4 \%)$, and American shad $(0.3 \%)$ (Table 2$)$. Wounded fishes and western river lamprey were both caught during 11 cruises (but not necessarily in the same haul) and were caught together in the same haul 5 times, including one western river lamprey (144 mm TL) that was observed attached to an American shad (127 mm FL) when a net was retrieved.

There were clear seasonal trends in the frequency of fishes observed with lamprey wounds (Fig. 4). Three of 4 fish species that were frequently wounded (American shad, Pacific herring, and shiner perch) displayed the highest rates of lamprey wounds in mid-summer. In contrast, wound rates for subyearling Chinook salmon were highest in September and October, because several wounded individuals were observed during time periods when relatively few Chinook salmon were caught. The maximum wound rate for shiner perch $(13.1 \%$ of individuals caught over a 2 -week period were wounded) was much higher than maximum rates observed for other fishes $(\leq 2.3 \%)$.

Comparisons of the size of fishes with and without wounds indicated apparent size selectivity for small American shad but not for other common hosts (Fig. 5). American shad with lamprey wounds (mean: 113.4 mm FL; $n=68$ ) were smaller than those without wounds (143.2 $\mathrm{mm} \mathrm{FL} ; n=2784$ ) when all cruises were considered together (Friedman: $Q=14.0, P<0.05$ ). Wounded American shad were also smaller than unwounded shad when each cruise was evaluated independently, although these differences were statistically significant at $P<0.10$ in only 6 of 15 cruises (KW: $Z \geq 1.7$ ) as a result of low statistical power. In contrast, there was no statistical difference in size between wounded and unwounded subyearling Chinook salmon (mean size of wounded: $110.9 \mathrm{~mm} \mathrm{FL}, n=33$; mean size of unwounded: $105.1 \mathrm{~mm}$ FL, $n=2419$ ), Pacific herring (mean size of wounded: $115.1 \mathrm{~mm} \mathrm{FL}, n=8$; mean size of unwounded: $108.0 \mathrm{~mm} \mathrm{FL}, n=578$ ), or shiner perch (mean size of wounded: $95.9 \mathrm{~mm}$ FL, $n=24$; mean size of unwounded: $96.8 \mathrm{~mm}$ FL, $n=660$ ) (KW: $Z<1.5, P>0.10$; Friedman: $Q<1.0, P>0.10$; Fig. 5). It was notable that the largest individuals of commonly wounded species did not have wounds: this observation was most pronounced for American shad $>190 \mathrm{~mm}$ FL, but it was also observed in Chinook salmon $>168 \mathrm{~mm} \mathrm{FL}$, and Pacific herring $>140$ mm FL (Fig. 5).

\section{Discussion}

\section{Lamprey in the Columbia River estuary}

In two studies separated by 20 years both western river and Pacific lampreys were caught in the Columbia River estuary at similar locations, depths, and seasons. Pacific lamprey adults had the highest densities in January and February but were present through May (Fig. 2), presumably as they moved upstream through the estuary during prespawning migration (Moser et al., 2015). Pacific lamprey juveniles were most abundant in December but were present through June, likely corresponding with outmigration from riverine rearing areas (Beamish, 1980). Western river lamprey were caught in the estuary from April through September (Fig. 2)-a result that is consistent with the concept that this species resides and feeds in estuarine habitats (Beamish, 1980; Bond et al., 1983). Individuals of 


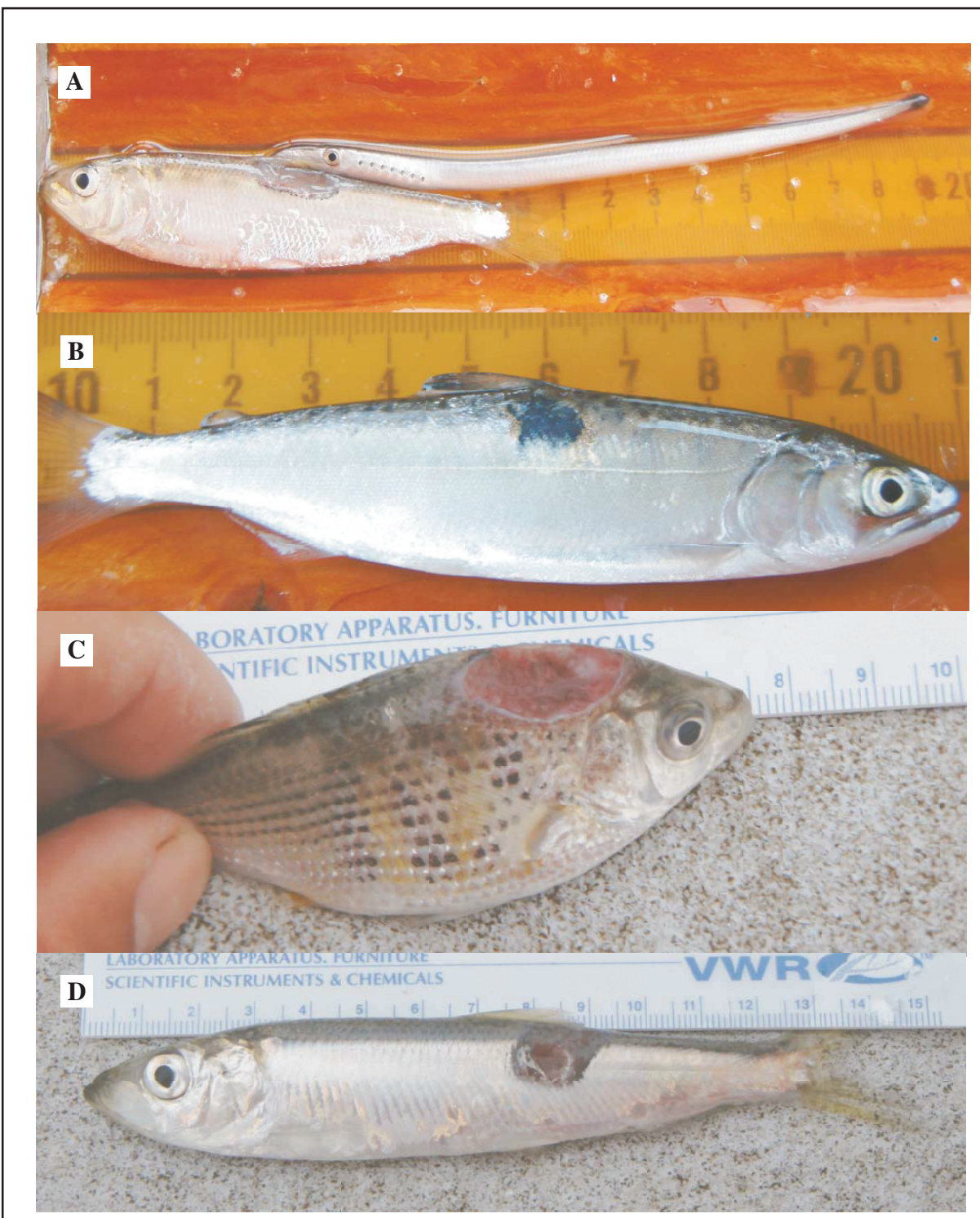

Figure 3

Examples of lamprey wounds observed on (A) American shad (Alosa sapidissima), (B) Chinook salmon (Oncorhynchus tshawytscha), (C) shiner perch (Cymatogaster aggregata), and (D) Pacific herring (Clupea pallasii) caught in the lower Columbia River estuary during 2008-2012. The western river lamprey (Lampetra ayresii) in panel A was observed attached to the American shad.

both species were found throughout the estuary (rkm 5-53) (Fig. 1).

The winter-early spring timing of the occurrence of Pacific lamprey adults observed in our analysis is earlier than the timing previously reported for adults in the Columbia River and other rivers, although limited winter sampling makes comparisons problematic. In the Columbia River estuary, adult Pacific lamprey were observed during April-May by Dawley et al. ${ }^{4}$, but

${ }^{4}$ Dawley, E. M., R. Ledgerwood, and A. L. Jensen. 1985.
Dawley et al. were not sampled during winter or early spring. Adults have been counted crossing Bonneville Dam (rkm 235) between early May and late September, and the highest counts were recorded in July (Fish Passage Center [FPC] query page for dam counts of

Beach and purse seine sampling of juvenile salmonids in the Columbia River estuary and ocean plume, 1977-1983: Volume I: Procedures, sampling effort, and catch data. Final Report of Research funded by Bonneville Power Administration. [Available from Northwest Fish. Sci. Cent., Natl. Mar. Fish. Serv., 2725 Montlake Blvd. E., Seattle, WA 98112-2097.] 


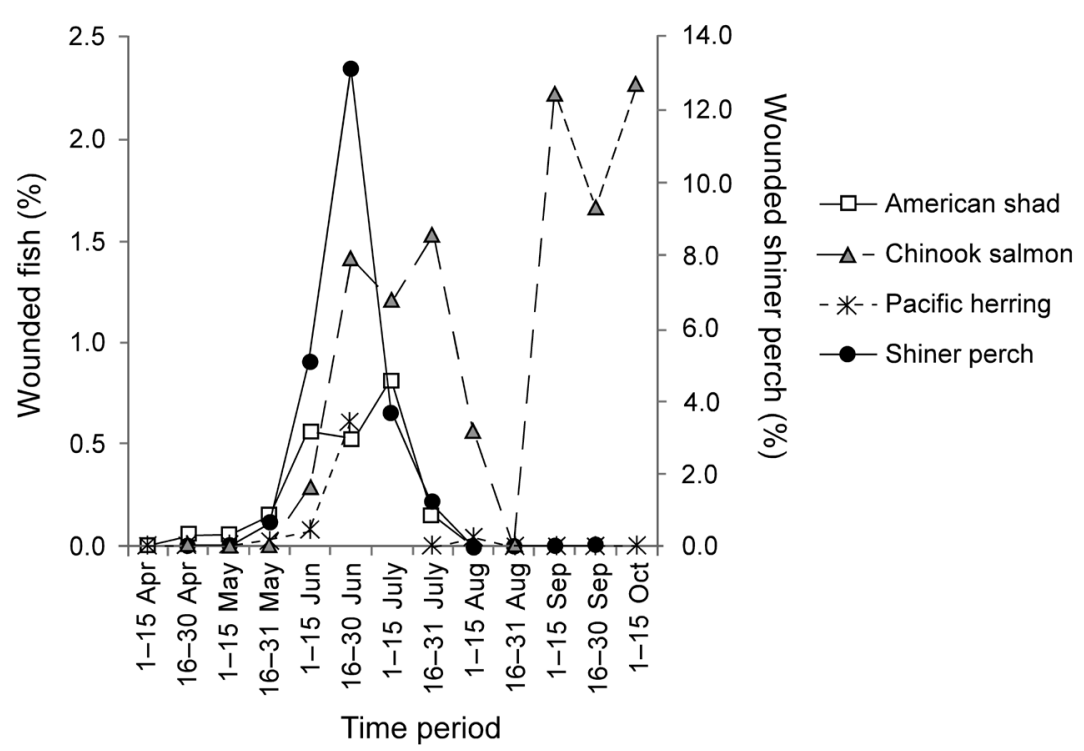

Figure 4

Mean percentage of fish observed with lamprey wounds by 2 -week time periods during 2008-2012 for American shad (Alosa sapidissima), shiner perch (Cymatogaster aggregata), and Pacific herring (Clupea pallasii) and during 2006-2012 for Chinook salmon (Oncorhynchus tshawytscha) in the lower Columbia River estuary. Note that the axis for shiner perch is on the right side.

show an abrupt increase in midApril, soon after sampling commences in the spring (FPC smolt data query page, http://www.fpc. org/smolt/SMP_queries.html, accessed August 2013). Hayes et al. (2013) indicated that, in Puget Sound, downstream migration of Pacific lamprey juveniles occurs during fall or winter, on the basis of the absence of that life stage in salmon smolt traps, which typically only operate during spring and summer. Moreover, in Tenmile Creek on the Oregon coast, van de Wetering (1998) observed peak downstream migration of juvenile Pacific lamprey during November and December, slightly earlier than the timing observed in our analysis for the Columbia River estuary but consistent with the patterns described by Kan (1975) for large versus small rivers. Similar winter-spring timing of ocean entry has been reported for juvenile Pacific lamprey in California (Moyle, 2002) and a slightly later timing (through mid-summer) in

adult salmon, http://www.fpc.org/adultsalmon/adultqueries/adult_table_submit.html, accessed August 2013), indicating that it may take $2-5$ months for adults to migrate from the estuary to the dam. In British Columbia, it appears that adult Pacific lamprey re-enter freshwater typically between April and September, later than they do in the Columbia River estuary (Beamish, 1980; Beamish and Levings, 1991). In California, adult Pacific lamprey move upstream between early March and late June, although earlier (December and January) and later (July-November) migration timing has also been reported (Chase, 2001; Moyle, 2002; Moyle et al., 2009). Although available data are geographically limited and are often based on 1 or 2 years of study (including our study), there appears to be considerable regional or annual variation in the timing of movement of adult Pacific lamprey from marine to freshwater habitats.

In contrast to the variation among studies in timing of adult migrations, our estimate of migration timing for juvenile Pacific lamprey during winterspring (Fig. 2) is consistent with observations from other studies; timing of this downstream migration is thought to be driven by river discharge (Beamish and Levings, 1991; van de Wetering, 1998; Moyle, 2002). Kostow $^{1}$ reported outmigration of Pacific lamprey (often mixtures of ammocoetes and juveniles) during fall, winter, and spring at locations throughout the Columbia River basin. Counts of "juvenile lamprey" (species were not identified) made at Bonneville Dam
British Columbia (Beamish 1980; Beamish and Levings, 1991).

The presence of western river lamprey in the Columbia River estuary from spring through fall (Fig. 2) is also similar to timing reported in other studies. Bond et al. (1983) reported western river lamprey in the Columbia River estuary, in Yaquina Bay on the Oregon coast, and nearby in marine waters from May through September. Hayes et al. (2013) stated that western river lamprey juveniles were common in downstream salmon smolt traps in Puget Sound in all months of operation (February-August), and the highest abundances occurred during June-August. For western river lamprey populations in Canada, Beamish (1980) reported the highest abundances in the Fraser River estuary in late May and in the Fraser River plume from early May through early July.

Upstream migration of adult western river lamprey is reported to occur from September through late winter in both the Fraser and Columbia rivers (Beamish, 1980; Bond et al., 1983). Our observation of an abrupt absence of western river lamprey in the Columbia River estuary beginning in October (Fig. 2) is consistent with this timing. However, neither the locations where western river lamprey go to spawn once they leave the estuary nor the total abundance of this species in the Columbia River (or other coastal rivers) are known (Kostow1; Mesa and Copeland, 2009). This information is especially needed to avoid misidentification of early life stages of lampreys in the field (Mesa and Copeland, 

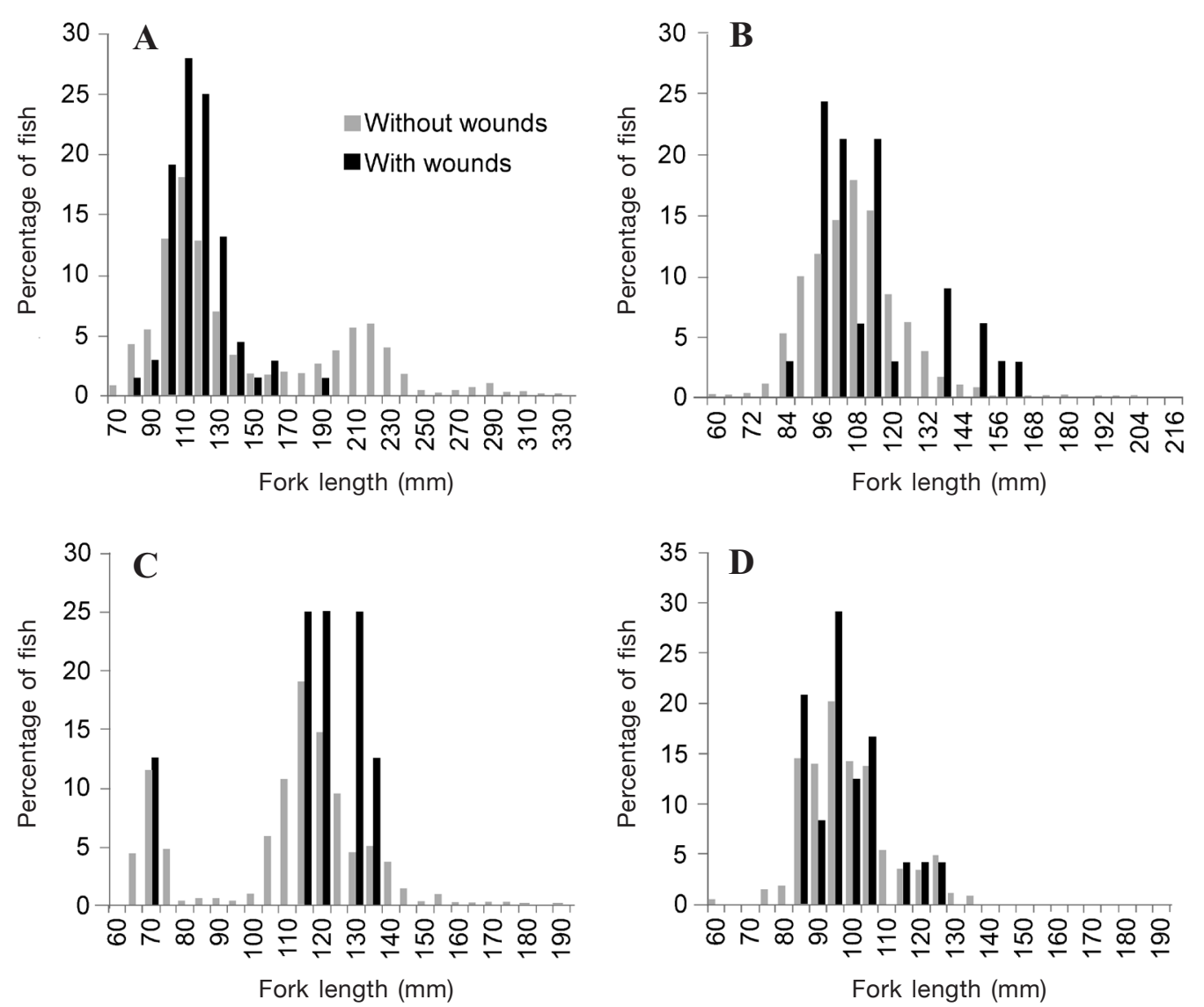

Figure 5

Comparison of the size frequency of (A) American shad (Alosa sapidissima), (B) Chinook salmon (Oncorhynchus tshawytscha), (C) shiner perch (Cymatogaster aggregata), and (D) Pacific herring (Clupea pallasii), with and without lamprey wounds. These fishes were collected in the lower Columbia River estuary during 2008-2012 or 2006-2012 (Chinook salmon only).

2009), given the often incorrect assumption that all juvenile lampreys are Pacific lamprey (Kostow ${ }^{1}$; Mesa and Copeland, 2009) and the difficulties of identifying small ammocoetes to species (Goodman et al., 2009).

The catch of each lamprey group (western river lamprey and Pacific lamprey juveniles and adults) in the CREDDP study was different with gear type, and the variation between groups due to gear type was mirrored by purse seine catches in the EPS study. In the CREDDP, catches of adult Pacific lamprey were more frequent in purse seines than in trawls, Pacific lamprey juveniles were caught more often in trawls than in purse seines, and catch of western river lamprey was fairly even between the 2 gear types (Table 1, Fig. 2). Accordingly, the near absence of Pacific lamprey in the EPS study was more likely due to a lack of sampling in winter and early spring, when the species was most abundant, and to an exclusive use of purse seines, which caught few juveniles, than due to low densities.

These gear-specific differences likely reflect the location of lampreys (or their hosts) in the water column.
Higher catches of Pacific lamprey juveniles in bottom trawls, compared with catches in purse seines, indicate that this species is demersal (or attached to demersal hosts), in contrast to Pacific lamprey adults and western river lamprey (or their hosts), which were readily caught by pelagic purse seines. In addition, several studies also have shown that catches of lampreys increase with water depth (e.g., Dawley et al. ${ }^{4}$, Beamish and Youson, 1987). This habitat preference may be responsible for the absence of lampreys during 20012002 in the EPS study, when depth at sampling sites was shallower than depths at sites during 2003-2012, and for low catches (4 individuals) in shallow fyke nets and beach seines during the CREDDP study. Whether lampreys are attached to hosts or free swimming at these life history stages and how these behaviors vary geographically within and between estuaries must be determined to understand lamprey habitat use and requirements in estuaries.

The average sizes that we report for Pacific lamprey adults (596 mm TL) and juveniles (133 mm TL) 
Table 3

Comparison of the total lengths of Pacific lamprey (Entosphenus tridentatus) adults and juveniles and western river lamprey (Lampetra ayresii) reported in the literature and observed in our analysis of data sets from studies in the lower Columbia River estuary during 1980-1981 and 2001-2012. $-=$ no data were available.

\begin{tabular}{|c|c|c|c|}
\hline Species and location & $\begin{array}{l}\text { Mean length } \\
(\mathrm{mm})\end{array}$ & $\begin{array}{r}\text { Range } \\
(\mathrm{mm})\end{array}$ & Source \\
\hline \multicolumn{4}{|l|}{ Pacific lamprey adults } \\
\hline Columbia River estuary & 596 & $401-745$ & This analysis \\
\hline Columbia River, John Day River & - & $610-725$ & Bayer et al. ${ }^{1}$ \\
\hline British Columbia rivers & $190-640$ & $130-720$ & Beamish, 1980 \\
\hline Fraser River, British Columbia & 337 & $273-453$ & Beamish and Levings, 1991 \\
\hline Puget Sound rivers & 227 & $194-274$ & Hayes et al., 2013 \\
\hline Oregon \& N. California & 516 & $393-620$ & Kan, 1975 \\
\hline California rivers & - & $300-760$ & Moyle, 2002 \\
\hline Santa Clara River & $593-610$ & $485-800$ & Chase, 2001 \\
\hline \multicolumn{4}{|l|}{ Pacific lamprey juveniles } \\
\hline Columbia River estuary & 133 & $102-157$ & This analysis \\
\hline British Columbia rivers & $120-140$ & $47-160$ & Beamish, 1980 \\
\hline Fraser River, British Columbia & $106-140$ & - & Beamish and Levings, 1991 \\
\hline Skeena River, British Columbia & - & $115-155$ & Farlinger and Beamish, 1984 \\
\hline Puget Sound rivers & 125 & - & Hayes et al., 2013 \\
\hline Tenmile Creek, Oregon & - & $130-140$ & van de Wetering, 1998 \\
\hline Oregon rivers & 120 & $96-155$ & Kan, 1975 \\
\hline \multicolumn{4}{|l|}{ Western river lamprey } \\
\hline Columbia River estuary & 198 & $102-324$ & This analysis \\
\hline Columbia River estuary & $158-268$ & $115-310$ & Bond et al., 1983 \\
\hline Fraser River & 114 & $40-190$ & Beamish, 1980 \\
\hline Strait of Georgia & 227 & $100-290$ & Beamish, 1980 \\
\hline Puget Sound rivers & 154 & $104-277$ & Hayes et al., 2013 \\
\hline Yaquina Bay, Oregon & $179-218$ & $133-255$ & Bond et al., 1983 \\
\hline California rivers & - & $250-310$ & Moyle, 2002 \\
\hline
\end{tabular}

${ }^{1}$ Bayer, J. M., T. C. Robinson, and J. G. Seelye. 2000. Upstream migration of Pacific lampreys in the John Day River: behavior, timing, and habitat use, 46 p. Bonneville Power Administration Report DOE/ BP-26080-1. [Available from https://pisces.bpa.gov/release/documents/documentviewer.aspx?doc=26080-1].

and for western river lamprey (198 $\mathrm{mm}$ TL) are generally larger than the sizes reported for populations from British Columbia to California (Table 3). However, direct comparisons are challenging because of rapid growth during some life history stages and declines in size (shrinking) during others, along with variation in distances of sampling locations from the ocean. Our maximum measured lengths for adult Pacific $(745 \mathrm{~mm}$ TL) and western river lamprey (324 mm TL) were near or larger than the maximum sizes reported by common fish identification guides (e.g., Hart, 1973; Mecklenburg et al., 2002; Wydoski and Whitney, 2003), indicating that the Columbia River estuary may have unusually large individuals of both species. Adult Pacific lamprey in the Columbia River with longer migrations tend to be larger than adults with shorter migrations (Kan, 1975; Keefer et al., 2009) - a relationship that has a strong genetic basis (Hess et al., 2014). Consequently, although the larger size of Pacific lamprey in the Columbia River than the size of Pacific lamprey in other rivers may be explained by genetic adaptations to long migrations, it remains unclear whether similar adaptations or other factors, such as older age at maturity, are responsible for the large size of western river lamprey in the Columbia River estuary.

\section{Fishes with lamprey wounds}

We observed lamprey wounds on 8 species of fishes in the Columbia River estuary. We believe the majority of these wounds resulted from predation by western river lamprey, rather than by Pacific lamprey, because of 1) the seasonal overlap with western river lamprey and apparent absence of juvenile Pacific lamprey during summer, 2) wound locations on the dorsal surfaces of fishes (versus ventral surfaces for predation by Pacific lamprey; Beamish, 1980; Cochran, 1986; Clemens et al., 2010), and 3) wounds that were elongated rather than circular and did not completely penetrate the muscle layer (Fig. 3; Beamish, 1980; Beamish and Neville, 1995; Murauskas et al., 2013). We observed no wounds that we were confident were due to Pacific lamprey. 
Lamprey wounds have been previously reported on several of the species we observed, including Pacific herring and juvenile Chinook salmon (Beamish and Neville, 1995; Orlov et al., 2009), and identifiable remains of American shad, Pacific herring, and juvenile salmon (tentatively identified as chum salmon [O. keta] and steelhead) were described from stomachs of western river lamprey (Bond et al., 1983). We provide the first report of lamprey wounds on shiner perch, surf smelt, and longfin smelt. However, we did not observe lamprey wounds on species that are common lamprey prey in the Strait of Georgia, including coho, yearling Chinook, and chum salmon (Beamish and Neville, 1995), despite catching thousands of yearling Chinook and coho salmon and hundreds of chum salmon each spring (Weitkamp et al., 2012). Wound rates for commonly wounded species reported from the Fraser River plume (10-21\% of fish caught) (Beamish and Neville, 1995) are much higher than the rates we observed (Table 2). It is not known whether differences in host species and wound rates between the Columbia and Fraser River estuaries are due to differences in physical habitats, lamprey behavior or population sizes, fish assemblage composition, or other differences between the 2 estuarine systems.

We suspect that the hosts we observed were vulnerable to lamprey attacks because of both their size and habitat selection. Commonly wounded fishes were relatively large and had high temporal overlap with western river lamprey in the estuary. In contrast, small ( $<90 \mathrm{~mm}$ FL, $5 \mathrm{~g}$ ) yet abundant juvenile surf smelt, chum salmon, and threespine stickleback (Gasterosteus aculeatus) were not observed with wounds, likely because they were too small to serve as hosts for western river lamprey. The absence of wounds on most juvenile coho salmon, yearling Chinook salmon, and steelhead despite their relatively large size (>130 mm FL, $20 \mathrm{~g}$ ) may be a result of rapid movement through the Columbia River estuary (Welch et al., 2008; Harnish et al., 2012) that provided limited opportunity for predation. Lack of lamprey wounds on larger American shad or extremely abundant northern anchovy (Engraulis mordax) may also reflect limited opportunity: large shad may have just re-entered freshwater and were moving rapidly upstream (Hammann, 1981), and northern anchovy are a marine species that typically enter the estuary only during high tides (Weitkamp et al., 2012).

Murauskas et al. (2013) argued that the abundance of adult Pacific lamprey in the Columbia River is at least partially controlled by the abundance of their hosts during their parasitic phase in marine environments. If this idea applies equally to western river lamprey in the Columbia River estuary, we expect that their population should be relatively healthy because of the abundance of potential prey in the estuary. In particular, it has been suggested that forage fishes in the estuary have greatly increased in abundance since the late $1970 \mathrm{~s}$ as a result of alternations in river flow from main stem dams (Weitkamp et al., 2012).
Furthermore, the population of nonindigenous American shad-the species most commonly observed with lamprey wounds-has numbered in the millions of fish in the Columbia River in recent years (Hasselman et al., 2012a). Although there are concerns about potentially negative ecological impacts to native species from abundant American shad in the Columbia River (Hasselman et al., 2012b), our data indicate that high American shad abundance may be beneficial to western river lamprey by providing a plentiful and ideal-size resident host. American shad may also shield native species from potentially lethal predation by western river lamprey. The recent catch of several western river lamprey and an American shad with lamprey wounds in the Yaquina River estuary (Cornwell ${ }^{5}$ ) suggests that these benefits are not restricted to the Columbia River but may be occurring in other coastal estuaries where both species are present. Clearly, many aspects of lamprey-host relationships are poorly understood and deserve further investigation.

Finally, our analysis of lampreys in the Columbia River estuary, although far from comprehensive, begins to fill a critical information gap about lampreys in estuaries in general and in the Columbia River estuary in particular (Mesa and Copeland, 2009). As with other lamprey studies (e.g., Hayes et al., 2013), we relied on data from research projects where-although lampreys were caught and recorded-lampreys were not specifically the focus of the study. In addition, in the CREDDP, lampreys and other fishes were sampled only during fall and winter of a single year; therefore we were unable to estimate interannual variability in the timing of winter migrations of Pacific lamprey. Dedicated, multiyear, lamprey-centric studies with appropriate gear and sampling schedules would obviously be much more effective for collecting lamprey biological and ecological data (Moser and Close, 2003). Despite its limitations, however, our analysis provides important information about lampreys during a life stage about which very little is known in the Columbia River estuary, and it adds to a growing body of knowledge that is essential to support the continued existence of these ancient species.

\section{Acknowledgments}

This study benefited from an exceptional field crew, which included M. Litz, A. Claiborne, S. Sebring, and A. Claxton, and from boat operators B. Kelly and R. Nelson. M. Moser provided encouragement for the project and guidance on the identification of lamprey wounds. This study was funded by the Northwest Fisheries Science Center and Bonneville Power Administration. The manuscript was greatly improved by constructive comments provided by R. Emmett, M. Moser, and 3 anonymous reviewers.

\footnotetext{
${ }^{5}$ Cornwell, T. 2014. Unpubl. data. Oregon Dep. Fish Wildl., 28655 Hwy. 34, Corvallis, OR 97333.
} 


\section{Literature cited}

Beamish, R. J.

1980. Adult biology of the river lamprey (Lampetra ayresi) and the Pacific lamprey (Lampetra tridentata) from the Pacific Coast of Canada. Can. J. Fish. Aquat. Sci. 37:1906-1923. Article

Beamish, R. J., and C. D. Levings.

1991. Abundance and freshwater migrations of the anadromous parasitic lamprey, Lampetra tridentata, in a tributary of the Fraser River, British Columbia. Can. J. Fish. Aquat. Sci. 48:1250-1263. Article

Beamish, R. J., and C. M. Neville.

1995. Pacific salmon and Pacific herring mortalities in the Fraser River plume caused by river lamprey (Lampetra ayresi). Can. J. Fish. Aquat. Sci. 52:644-650. Article

Beamish, R. J., and J. H. Youson.

1987. Life history and abundance of young adult Lampetra ayresi in the Fraser River and their possible impact on salmon and herring stocks in the Strait of Georgia. Can. J. Fish. Aquat. Sci. 44:525-537. Article

Bond, C. E., T. T. Kan, and K. W. Myers.

1983. Notes on the marine life of the river lamprey, Lampetra ayresi, in Yaquina Bay, Oregon, and the Columbia River estuary. Fish. Bull. 81:165-167.

Chase, S. D.

2001. Contributions to the life history of adult Pacific lamprey (Lampetra tridentate) in the Santa Clara River of Southern California. Bull. South. Calif. Acad. Sci. 100:74-85

Clemens, B. J., T. R. Binder, M. F. Docker, M. L. Moser, and S.

A. Sower.

2010. Similarities, differences, and unknowns in biology and management of three parasitic lampreys of North America. Fisheries 35:580-594. Article

Close, D. A., M. S. Fitzpatrick, and H. W. Li.

2002. The ecological and cultural importance of a species at risk of extinction, Pacific lamprey. Fisheries 27(7):19-25. Article

Cochran, P. A.

1986. Attachment sites of parasitic lampreys: comparisons among species. Environ. Biol. Fish. 17:71-79. Article

Farlinger, S. P., and R. J. Beamish.

1984. Recent colonization of a major salmon-producing lake in British Columbia by Pacific lamprey (Lampetra tridentatus). Can. J. Fish. Aquat. Sci. 41:278-285. Article

Goodman, D., A. P. Kinziger, S. B. Reid, and M. F. Docker. 2009. Morphological diagnosis of Entosphenus and Lampetra ammocoetes (Petromyzontidae), in Washington, Oregon, and California. Am. Fish. Soc. Symp. 72:223-232.

Hammann, M. G.

1981. Utilization of the Columbia River estuary by American shad, Alosa sapidissima (Wilson). M.S. thesis, 48 p. Oregon State Univ., Corvallis, OR.

Hart, J. L.

1973. Pacific fishes of Canada. Fish. Res. Board Can. Bull. 180, 740 p.

Hardisty, M. W.

2006. Lampreys: Life without jaws, 272 p. Forrest Text, Ceredigion, UK

Harnish, R. A., G. E. Johnson, G. A. McMichael, M. S. Hughes, and B. D. Ebberts.

2012. Effect of migration pathway on travel time and survival of acoustic-tagged juvenile salmonids in the Columbia River estuary. Trans. Am. Fish. Soc. 141:507-519. Article

Hasselman, D. J., R. A. Hinrichsen, B. A. Shields, and C. C. Ebbesmeyer.

2012a. The rapid establishment, dispersal, and increased abundance of invasive American shad in the Pacific Northwest. Fisheries 37:103-114. Article

2012b. American shad of the Pacific coast: a harmful invasive species or benign introduction? Fisheries 37:115-122. Article

Hayes, M. C., R. Hays, S. P. Rubin, D. M. Chase, M. Hallock, C. Cook-Tabor, C. W. Luzier, and M. L. Moser.

2013. Distribution of Pacific lamprey Entosphenus tridentatus in watersheds of Puget Sound based on smolt monitoring data. Northwest Sci. 87:95-105. Article

Hess, J. E., C. C. Caudill, M. L. Keefer, B. J. McIlraith, M. L. Moser, and S. R. Narum.

2014. Genes predict long distance migration and large body size in a migratory fish, Pacific lamprey. Evol. Appl. Article

Jackson, A. D., and M. L. Moser.

2012. Low-elevation dams are impediments to adult Pacific lamprey spawning migration in the Umatilla River, Oregon. N. Am. J. Fish. Manage. 32:548-556. Article

Kan, T. T.

1975. Systematics, variation, distribution, and biology of lampreys of the genus Lampetra in Oregon. Ph.D. diss., 194 p. Oregon State Univ., Corvallis, OR.

Keefer, M. L., M. L. Moser, C. T. Boggs, W. R. Daigle, and C. A. Peery.

2009. Effects of body size and river environment on the upstream migration of adult Pacific lampreys. N. Am. J. Fish. Manage. 29:1214-1224. Article

King, E. L., Jr.

1980. Classification of sea lamprey (Petromyzon marinus) attack marks on Great Lakes lake trout (Salvelinus namaycush). Can. J. Fish. Aquat. Sci. 37:19892006. Article

Mecklenburg, C. W., T. A. Mecklenburg, and L. K. Thorsteinson. 2002. Fishes of Alaska, 1116 p. Am. Fish. Soc. Press, Bethesda, MD.

Mesa, M. G., and E. S. Copeland.

2009. Critical uncertainties and research needs for the restoration and conservation of native lampreys in North America. Am. Fish. Soc. Symp. 72:311-321.

Moser, M. L., P. R. Almeida, P. S. Kemp, and P. W. Sorenson.

2015. Chapter 5: Lamprey spawning migration. In Lampreys: biology, conservation and control, vol. 1 (M. F. Docker, ed.), p. 215-264. Springer, Dordrecht, Netherlands. Article

Moser, M. L., and D. A. Close.

2003. Assessing Pacific lamprey status in the Columbia River basin. Northwest Sci. 77:116-125.

Moyle, P. B.

2002. Inland fishes of California, 502 p. Univ. Calif. Press, Berkeley, CA.

Moyle, P. B, L. R. Brown, S. D. Chase, and R. M. Quiñones. 2009. Status and conservation of lampreys in California. Am. Fish. Soc. Symp. 72:279-292.

Murauskas, J. G., A. M. Orlov, and K. A. Siwicke.

2013. Relationships between the abundance of Pacific lamprey in the Columbia River and their common hosts in the marine environment. Trans. Am. Fish. Soc. 142:143-155. Article

Orlov, A. M., R. J. Beamish, A. V. Vinnikov, and D. Pelenev. 2009. Feeding and prey of Pacific lamprey in coastal wa- 
ters of the western North Pacific. Am. Fish. Soc. Symp. 69:875-877.

Quinn, T. P.

2005. The behavior and ecology of Pacific salmon and trout, 320 p. Univ. Wash. Press, Seattle, WA.

Renaud, C. B.

1997. Conservation status of northern hemisphere lampreys (Petromyzontidae). J. Appl. Ichthyol. 13:143-148. Article

Scott, W. B., and E. J. Crossman.

1973. Freshwater fishes of Canada. Fish. Res. Board Can. Bull. 188, 966 p.

Siwicke, K. A.

2014. Relationships between anadromous lampreys and their host fishes in the eastern Bering Sea. M.S. thesis, 110 p. Univ. Alaska, Fairbanks, AK.

Sokal, R. R., and F. J. Rohlf.

1995. Biometry: the principles and practice of statistics in biological research, 3rd ed., 887 p. W. H. Freeman, New York.

Streif, B.

2009. Considering Pacific lampreys when implementing instream activities. Am. Fish. Soc. Symp. 72:255-268. van de Wetering, S. J.

1998. Aspects of life history characteristics and physiological processes in smolting Pacific lamprey, Lampetra tridentata, in a central Oregon coast stream. M.S. thesis, 59 p. Oregon State Univ., Corvallis, OR.

Weitkamp, L. A., P. B. Bentley, and M. N. C. Litz.

2012. Seasonal and interannual variation in juvenile salmonids and associated fish assemblage in open waters of the lower Columbia River estuary. Fish. Bull. 110:426-450.

Welch, D. W., E. L. Rechisky, M. C. Melnychuk, A. D. Porter, C.

J. Walters, S. Clements, B. J. Clemens, R. S. McKinley, and

C. Schreck.

2008. Survival of migrating salmon smolts in large rivers with and without dams. PLoS Biology 6(10):e265. Article

Wydoski, R. S., and R. R. Whitney.

2003. Inland fishes of Washington, 2nd ed., 384 p. Univ. Wash. Press, Seattle, WA.

Zar, J. H.

1984. Biostatistical analysis, 2nd ed., 718 p. PrenticeHall Inc., Englewood Cliffs, NJ. 